\title{
The Application of UV-Vis Spectroscopy in Instrumental Analysis Teaching
} Jiang Xipeng, Bi Hongmei*

College of science, Heilongjiang Bayi Agricultural University, Daqing 163319, PR China

DOI: $10.36347 /$ sipms.2020.v07i01.002

| Received: 19.01.2020 | Accepted: 26.01.2020 | Published: 30.01 .2020

*Corresponding author: Bi Hongmei

Abstract

Original Research Article

As in the course of instrumental analysis, the knowledge of UV-vis spectroscopy is very important, and the understanding of this part is not easy for students of chemistry major. We could contact the determination of edible pigments with UV-vis spectroscopy, which can enhance the quality of the instrumental analysis class, and enhance the study ability of students.

Keywords: Instrumental analysis, UV-vis spectroscopy, study ability.

Copyright @ 2020: This is an open-access article distributed under the terms of the Creative Commons Attribution license which permits unrestricted use, distribution, and reproduction in any medium for non-commercial use (NonCommercial, or CC-BY-NC) provided the original author and source are credited.

\section{INTRODUCTION}

Nowadays, the pressure of employment is more and more tight, and the requirements for the talented people are more and more strict. For a better employment and a brighter future, universities and colleges students should adapt lifelong study and social development; they should prepare requisite characters and crucial abilities. What is more important, the study ability in crucial abilities are needed urgently. How to develop the study ability effectively? How to connect the theory knowledge with the practical application? It needs the efforts from both the teachers and students. In order to enhancethe quality of chemical classes, teachers should give a coherent and a professional introduction in study method and technique. As in the course of instrumental analysis, the knowledge of UVvis spectroscopy is very important. And the understanding of instrumental theory, instructions of apparatus, notes in apparatus operation, and the application of UV-vis spectroscopy are not easy to understand. UV-vis spectroscopy can be widely used in various fields such as food and nutriology, medicine, detection of water quality, chemical industry, content analysis and etc. How to make them more easily understood? How to elevate the interest of students in this part of learning? We could contact the determination of edible pigments with UV-vis spectroscopy. The ediblepigments are important food additives added in beverages, which can make the beverages more attractive and delicious [1]. There are four edible pigments (carmine, amaranth, sun set yellow, lemon yellow) widely added in beverages. Therefore, it is necessary to give a delicate determination to guarantee the safety of the drinks [2, 3].

\section{MATERIALS AND METHODS Apparatus and reagents}

Spectrometer: IS5 FT-IR (Thermo Fisher) is applied in this experiment. Scan range from 400 to 4000 $\mathrm{cm}^{-1}$ with a resolution of $4 \mathrm{~cm}^{-1}$. Spectra were obtained from the accumulation of a total of 16 sans. UV-vis spectroscopy (UNICO 2802) is used for the detection of the content of edible pigments.

\section{Reagents}

All the reagents used in these experiments are of analytical grade, and the water used is deionized water. 


\section{RESULTS AND DISCUSSION}

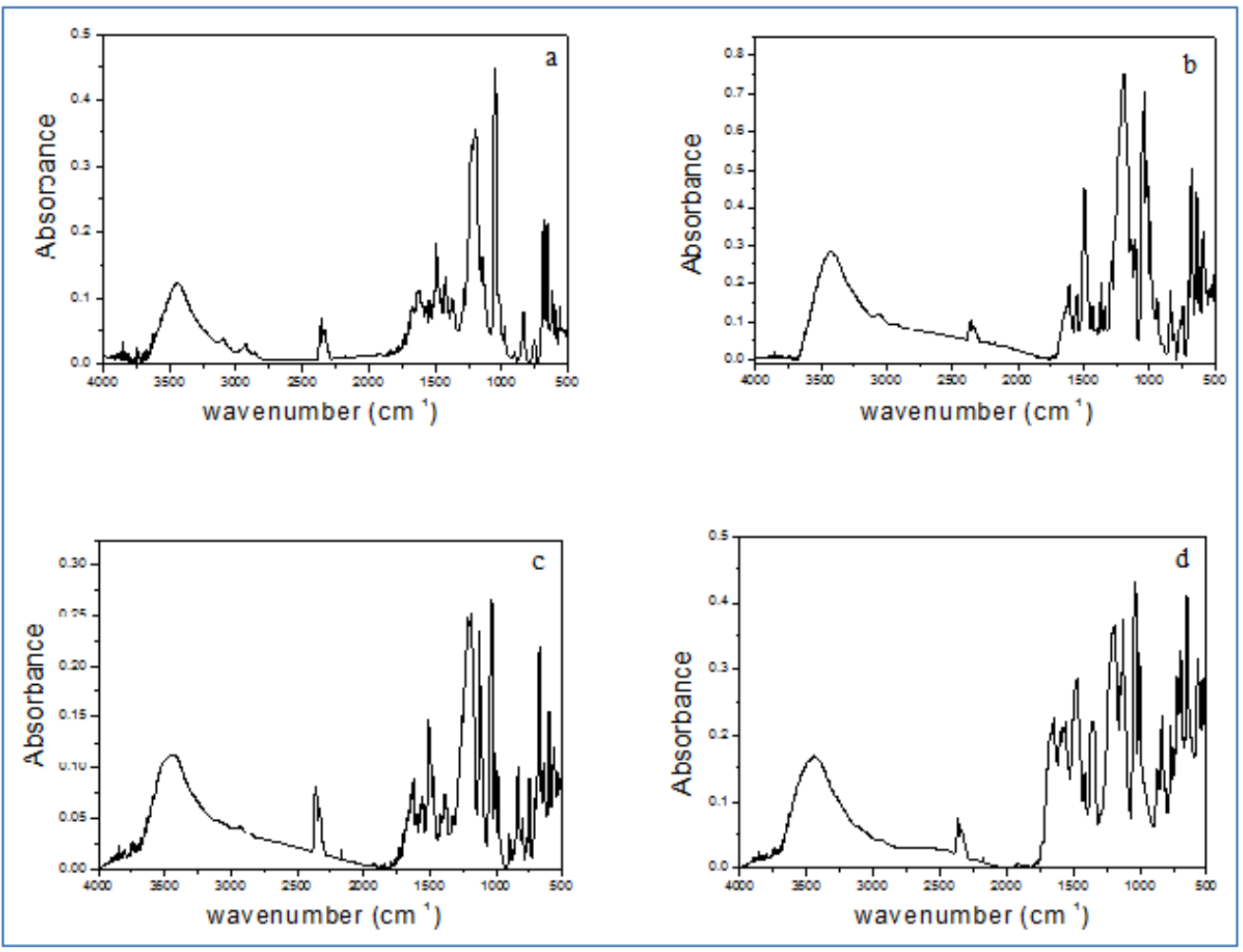

Fig-1: FR-IR spectra of the edible pigments of: a) carmine, b) amaranth, c) sun set yellow, d) lemon yellow
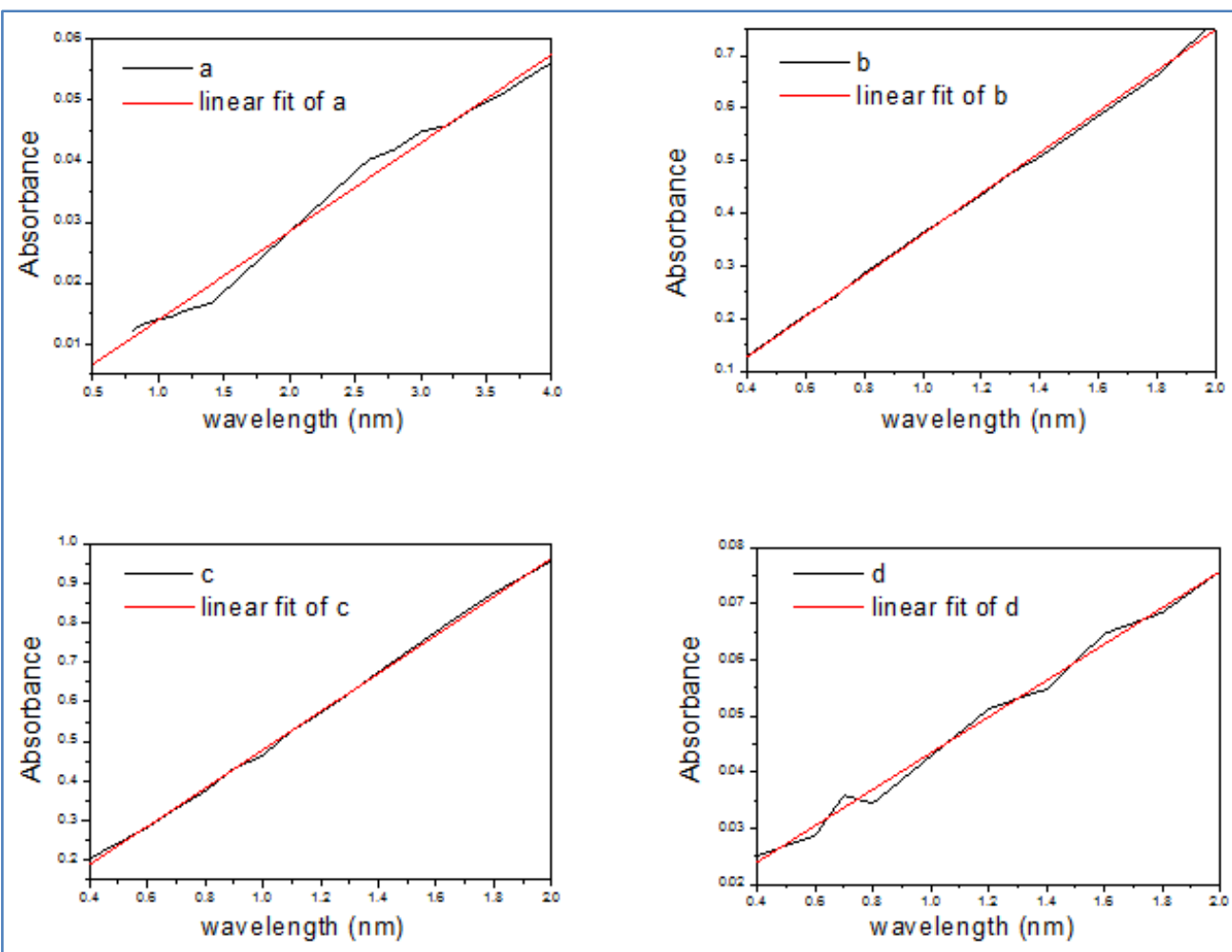

Fig-2: UV-vis absorption of edible pigments of: a) carmine, b) amaranth, c) sun set yellow, d) lemon yellow 


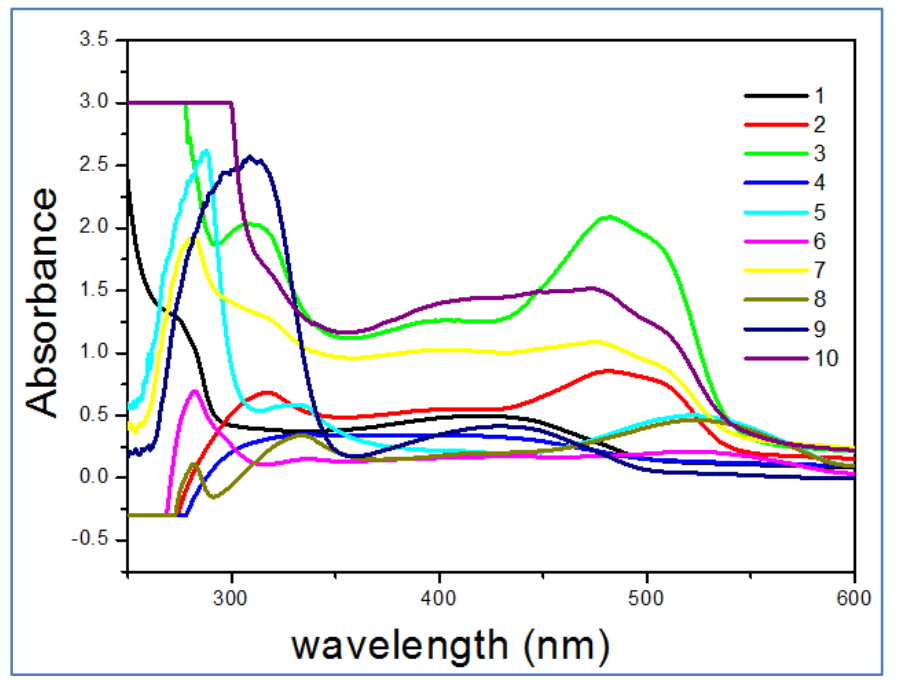

Fig-3: UV-vis absorption of 10 kinds of beverages purchased from supermarkets

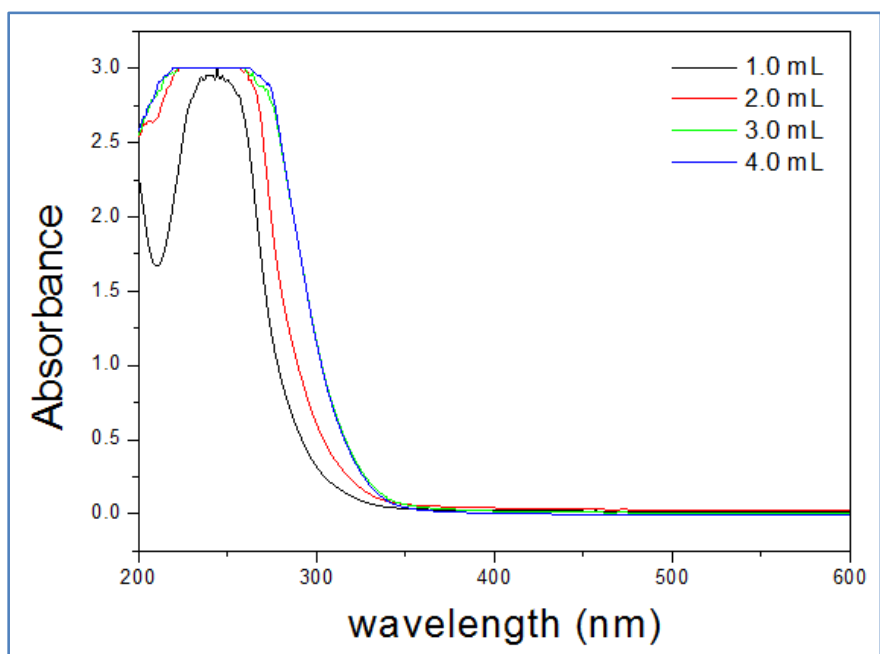

Fig-4: The choice of the concentration of reference solution

Table-1: The content of the edible pigments in 10 drinks purchased from supermarkets

\begin{tabular}{|l|l|l|l|}
\hline $\begin{array}{l}\text { Sample } \\
\text { No. }\end{array}$ & Type of pigments & $\begin{array}{l}\text { Content of } \\
\text { pigments(mg/L) }\end{array}$ & notes \\
\hline 1 & lemon yellow & 26.23 & Banana beverage of Brand MND \\
\hline 2 & sun set yellow & 1.94 & Sport beverage of Brand JDL \\
\hline 3 & sun set yellow & 5.18 & Orange beverage of Brand EST \\
\hline 4 & lemon yellow & 9.56 & lemon beverage of Brand EST \\
\hline 5 & amaranth & 1.49 & grape beverage of Brand MND \\
\hline 6 & lemon yellow, amaranth & $4.01,0.54$ & Water beverage of Brand MND \\
\hline 7 & lemon yellow,sun set yellow & $17.23,0.78$ & Orange beverage of Brand FD \\
\hline 8 & amaranth, lemon yellow & $1.20,3.07$ & Grape beverage of Brand FD \\
\hline 9 & carmine, lemon yellow & $21.12,8.25$ & Sport beverage of Brand HN \\
\hline 10 & $\begin{array}{l}\text { lemon yellow, sun set yellow, } \\
\text { carmine }\end{array}$ & $19.91,2.16,29.39$ & Orange beverage of Brand MND \\
\hline
\end{tabular}

The test of the four edible pigments by FR-IR spectroscopy

The four pigments are under the test of FT-IR, the relative results are shown in Fig.1,

Compared with the relative standard spectra, the pureness of is high. 
The standard working curves of the four edible pigments by $U V$-vis spectroscopy

The standard working curves are worked out by UV-vis spectroscopy, as in Fig. 2. The equation of linear regression of carmine is $\mathrm{y}=0.01454 \mathrm{x}-5.97122 \times 10^{-}$ $4 \quad\left(R^{2}=0.991\right)$; the equation of linear regression of amaranth is $\mathrm{y}=0.3889 \mathrm{x}-0.02854 \quad\left(\mathrm{R}^{2}=0.998\right)$; the equation of linear regression of sun set yellow is $\mathrm{y}=0.4836 \mathrm{x}-0.00503 \quad\left(\mathrm{R}^{2}=0.999\right)$; and that of lemon yellow is $\mathrm{y}=0.03236 \mathrm{x}+0.01103\left(\mathrm{R}^{2}=0.990\right)$.

The contents of the edible pigments in drinks purchased from supermarkets pigments by $U V$-vis spectroscopy

10 kinds of drinks are purchased from supermarkets. Different concentrations of drink samples are prepared, and then tested by UV-vis spectroscopy. As shown in Fig.3, the spectra of mixed pigments samples are different from those of single pigments. The obvious shifts are attributed to the influence of pigments. All the content results are listed in Table 1.

In the tests, there are some instructions needed to follow. The first one is the choice of reference solution. The ingredients of the beverages are very complicated because of many kinds of food additives. Many ingredients have characteristic adsorption peaks, such as various types of amino acid, inorganic salts, and other additives. Therefore, the choice of reference solution is very important, if the reference solution is chosen suitably, the determination results are reliable. After screen experiments in the tests, we apply a beverage with various kinds of additives but without any pigment added as reference solution. The concentration of reference solution is also studied. As shown in Fig.4, as the concentration increasing, the absorption value is increasing, and the concentration of curve 3 is defined as the optimum concentration for further detection. Secondly, for the accuracy of detection, some of the beverage samples should be filtered before tests in order to remove the pulp sediments. The concentration of beverages should be in the range of standard working curves. Therefore, some of the drink samples needs diluted before tests.

\section{CONCLUSIONS}

In this paper, students have a better understanding of the UV-vis test procedure. Firstly, the meanings of horizontal and the longitudinal coordinates in the UV spectrum are understood clearly. Secondly, the relative longitudinal coordinates under $\lambda_{\max }$ of different pigments are found out; thirdly, thanks to the standard working curves, the definite content of every pigment can be obtained. In the later data processing procedure, students have a better understanding of analysis spectrum, correction of base line, splitting peaks. That is to say, every number in the data contributes in the analysis. Teaching in this mode, students could have a better understanding in the learn of UV-vis spectroscopy.

\section{REFERENCES}

1. Amchova P, Kotolova H, Ruda-Kucerova J. Health safety issues of synthetic food colorants. Regulatory Toxicology and Pharmacology. 2015 Dec 1;73(3):914-22.

2. Perdomo Y, Arancibia V, Beltran OG and Nagles E. "Adsorption stripping determination of amaranth and tartrazine in drinks and grlatins using a screenprinted carbon electrode", Sensor. 2017; 17: 2665 2675.

3. Liu L, Mi Z, Li H, Li C, Hu Q, Feng F. Highly selective and sensitive detection of amaranth by using carbon dots-based nanosensor. RSC advances. 2019;9(45):26315-20. 